Journal of Applied Pharmaceutical Science Vol. 5 (08), pp. 105-113, August, 2015

Available online at http://www.japsonline.com

DOI: $10.7324 / \mathrm{JAPS} .2015 .50817$

ISSN 2231-3354 (cc) BY-NC-SA

\title{
Hepatotoxicity following separate administration of two phosphodiesterase-5 inhibitors (sildenafil \& tadalafil) and opioid (tramadol); evaluation of possible reversal following their withdrawal
}

\author{
Victor U. Nna ${ }^{1 *}$, Ubom P. Akpan ${ }^{2}$, Victoria E. Okon ${ }^{1}$, Item J. Atangwho ${ }^{3}$ \\ ${ }^{1}$ Department of Physiology, Faculty of Basic Medical Sciences, College of Medical Sciences, University of Calabar, P.M.B. 1115 Calabar, Cross River \\ State, Nigeria. ${ }^{2}$ Department of Physiology, Faculty of Basic Medical Sciences, College of Health Sciences, University of Uyo, Uyo, Akwa Ibom State, \\ Nigeria. ${ }^{3}$ Department of Biochemistry, Faculty of Basic Medical Sciences, College of Medical Sciences, University of Calabar, P.M.B. 1115 Calabar, Cross \\ River State, Nigeria.
}

\section{ARTICLE INFO \\ Article history: \\ Received on: 19/05/2015 \\ Revised on: 05/06/2015 \\ Accepted on: 27/06/2015 \\ Available online: 28/08/2015}

\section{Key words:}

Hepatotoxicity, liver, phosphodiesterase-5 inhibitors, sildenafil, tadalafil, tramadol \begin{abstract}
The use of phosphodiesterase-5 inhibitors (PDE5i) and tramadol in the absence of erectile and ejaculatory dysfunctions in Nigeria has become a norm. In this study, we comparatively assess the effects of chronic use of these drugs on hepatotoxicity. Fifty male albino wistar rats weighing 180-200g were randomly assigned into 5 groups ( $\mathrm{n}=10)$ as follows; control, sildenafil $(1 \mathrm{mg} / 100 \mathrm{~g}$ b.w), tadalafil $(1 \mathrm{mg} / 100 \mathrm{~g} \mathrm{~b} . \mathrm{w})$, tramadol (2mg/100g b.w) and sildenafil+tramadol treated group $(1 \mathrm{mg} / 100 \mathrm{~g}$ and $2 \mathrm{mg} / 100 \mathrm{~g}$ b.w, respectively). Drugs were orally administered, once, every two days for 8 weeks, at the end of which five animals were sacrificed per group (batch 1 ), while the remaining five animals per group were allowed for another 8weeks without drug administration (batch 2). Serum concentration of liver enzymes (AST, ALT and ALP) and bilirubin were assessed in both batches. Serum concentrations of AST, ALT, ALP, total bilirubin and unconjugated bilirubin were significantly $(\mathrm{p}<0.001)$ increased in all treated groups (batch 1), while conjugated bilirubin concentration was significantly $(\mathrm{p}<0.001)$ reduced in all treated groups, compared with control. Serum concentrations of AST and ALT were significantly reduced in sildenafil $(\mathrm{p}<0.01)$, tadalafil $(\mathrm{p}<0.05)$, tramadol $(\mathrm{p}<0.001)$ and sildenafil+tramadol $(\mathrm{p}<0.001)$ recovery groups, compared with their treated groups. Total and unconjugated bilirubin fractions were significantly $(\mathrm{p}<0.05$ and $\mathrm{p}<0.01$, respectively) reduced in tadalafil recovery group, compared with the treated group. Sildenafil+tramadol recovery group showed significantly $(\mathrm{p}<0.001)$ reduced total and unconjugated bilirubin concentrations, compared with the treated group. Chronic administration of PDE5i and tramadol reversibly altered liver functions.
\end{abstract}

\section{INTRODUCTION}

Sildenafil citrate (common name-viagra) and tadalafil (common name-cialis) are widely used for treatment of erectile dysfunction (ED) of various etiologies (Nurnberg et al., 2001; Benchekroun et al., 2003; Gopalakrishnan et al., 2006; Kokkinos et al., 2015). These drugs belong to a class of drugs called phosphodiesterase-5 inhibitors (PDE5i), owing to their potent and selective inhibition of phosphodiesterase type 5 enzyme that breaks down cyclic guanosine monophosphate (cGMP) (Boolell et al., 1996). Inhibiting the degradation of c GMP prolongs

\footnotetext{
* Corresponding Author

Victor U. Nna, Department of Physiology, Faculty of Basic Medical Sciences, College of Medical Sciences, University of Calabar, P.M.B. 1115 Calabar, Cross River State, Nigeria.Email: victor2nna@gmail.com
}

erection, and forms the basis of the efficacy of this class of drugs. Undoubtedly, erectile dysfunction most often occurs together with premature ejaculation (Rosen et al., 2004). Several studies have reported the beneficial effect of the use of tramadol hydrochloride (an opioid drug) to delay ejaculation (Safarinejad \& Hosseini, 2006; Salem et al., 2008; Althof et al., 2010; Rowland et al., 2010). This later informed the use of tramadol in patients suffering premature ejaculation. Most recently, there has been an upsurge in the abuse of ED medications. In a population-based study reported by Nna et al., (2014a, b) in Calabar, Nigeria, the young population indulged more in the use of ED medications, even in the absence of erectile or ejaculatory dysfunction.

Their motivation for using these medications revolve round a number of factors, however, the most recurrent factor as reported in that study is; a quest for a bigger genital size. 
Users of sex stimulants have reported their side effects to include stomach pain and headache (Nna et al., 2014a). It is conceivable that there are other side effects which may not be easily discernible like headache and stomach pain, but may be serious enough to affect one's health. It is against this backdrop that the present study seeks to ascertain the effect of chronic use of these drugs (sildenafil, tadalafil and tramadol) on hepatotoxicity, since the liver will be constantly bombarded with large concentrations of these medications. Also, the present study investigates the possibility of reversal of hepatotoxicity following the withdrawal of these drugs.

\section{MATERIALS AND METHODS}

\section{Animal preparation and protocol}

Fifty (50) male albino wistar rats weighing $180-200 \mathrm{~g}$ were used for this study. The animals were purchased from the Department of Agriculture, in University of Calabar, and housed in well ventilated cages (wooden bottom and wire mesh top) in the animal house of the College of Medical Sciences, University of Calabar. The animals were allowed access to rat feed and water $a d$ libitum, and exposed to 12/12 hours light/dark cycle. The animals were allowed 7 days for habituation before commencement of the research. Indeed, the animals were handled in accordance with the laid down principles for animal care as instituted by Helsinki in 1964.

\section{Experimental design and drugs used}

The rats were randomly assigned into 5 groups $(\mathrm{n}=10)$ as shown in table 1 . The drugs used in this study were; sildenafil citrate (Maxheal Laboratories Pvt Ltd, India), tadalafil (Pfizer, India) and tramadol hydrochloride (Glow Pharma Pvt Ltd, India). The different drugs were administered per oral route, once, every two days, for 8 weeks. This design was selected because it is conceivable that these classes of drugs may not be taken daily. At the end of 8 weeks of treatment, five animals were randomly selected and sacrificed from each group, blood samples were collected for assessment of serum bilirubin concentration and liver enzyme activities. The remaining 5 animals per group were allowed for another 8 weeks, without treatment (recovery phase), but were allowed access to feed and water ad libitum.

\begin{tabular}{lcl} 
Table 1: Experimental design. & \\
\hline \multicolumn{1}{c}{ Group } & $\begin{array}{c}\text { No. of } \\
\text { animals }\end{array}$ & \multicolumn{1}{c}{ Treatment } \\
\hline 1 (NC) & 10 & Distil water \\
2 (Sildenafil) & 10 & Sildenafil (dose $=1 \mathrm{mg} / 100 \mathrm{~g}$ b.w.) \\
3 (Tadalafil) & 10 & Tadalafil (dose $=1 \mathrm{mg} / 100 \mathrm{~g}$ b.w.) \\
4 (Tramadol) & 10 & Tramadol (dose $=2 \mathrm{mg} / 100 \mathrm{~g}$ b.w.) \\
5 (Sild.+Tram.) & 10 & $\begin{array}{c}\text { Sildenafil \& Tramadol } \\
\text { (dose }=1 \mathrm{mg} / 100 \mathrm{~g} \text { b.w. \& } 2 \mathrm{mg} / 100 \mathrm{~g} \\
\end{array}$ \\
& & b.w., respectively) \\
\hline
\end{tabular}

\section{Collection of blood samples}

Under chloroform anaesthesia, blood samples were collected from the animals through cardiac puncture into prelabelled sample bottles, and allowed to clot for 30 minutes. The clotted blood samples were centrifuged to separate the cells from the serum. Sera were then aspirated into labelled vials and stored in the freezer at $-15^{\circ} \mathrm{C}$ pending usage.

\section{Measurement of serum concentration of liver enzymes}

Serum concentrations of aspartate aminotransferase (AST), alkaline phosphatase (ALP) and alanine aminotransferase (ALT) were determined using the method described by Reitman and Frankle (1957), modified by Bhutia et al., (2006).

\section{Measurement of serum bilirubin concentration}

Serum bilirubin concentration was measured using the method described by Sherlock and Lunec (1951).

\section{Percentage conjugation of bilirubin}

The percentage of serum total bilirubin that was conjugated (SCB) was obtained mathematically using the formula below, as previously used by Nna et al., (2014c).

Percentage $\mathrm{SCB}=$

$\frac{\text { Serum concentrated bilirubin concentration }}{\text { Serum total bilirubin concentration }} \times 100$

\section{Statistical analysis}

The data obtained from this study are presented as mean \pm SEM. The one way analysis of variance (ANOVA) was used to analyse the data, following by post hoc multiple comparison (least square difference procedure). Also, student's $\mathrm{t}-$ test was used to compare the difference between treated and recovery groups. $P$ values $<0.05$ were considered significant. Computer software, SPSS (version 17.0) and Microsoft excel (2010 version) analyser were used for the analysis of data.

\section{RESULTS}

Comparison of serum concentration of liver enzymes and bilirubin in the different experimental groups following 8 weeks of treatment with the various drugs Serum AST concentration

After 8 weeks of drug administration, serum AST concentration for control, sildenafil, tadalafil, tramadol and sildenafil + tramadol treated groups were $16.40 \pm 1.54,39.60 \pm$ $3.57,84.20 \pm 3.28,104.40 \pm 3.11$ and $57.20 \pm 4.57 \mathrm{IU} / \mathrm{L}$, respectively. Serum AST concentration was significantly $(\mathrm{p}<0.001)$ increased in all treated groups, compared with control group. Serum AST concentration was significantly $(\mathrm{p}<0.001)$ higher in tadalafil, tramadol and sildenafil + tramadol treated groups, compared with sildenafil treated group. It was also significantly $(\mathrm{p}<0.001)$ higher in tramadol treated group, compared with tadalafil treated group. Serum AST concentration was significantly $(\mathrm{p}<0.001)$ lower in sildenafil + tramadol treated group, compared with tadalafil and tramadol treated groups (table 2). 


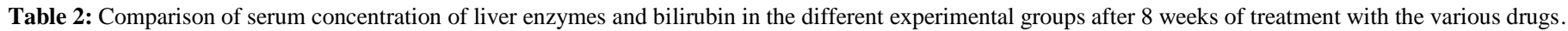

\begin{tabular}{|c|c|c|c|c|c|}
\hline Parameter & Control & Sildenafil & Tadalafil & Tramadol & Sild. + Tram. \\
\hline AST (IU/L) & $16.40 \pm 1.54$ & $39.60 \pm 3.57^{\mathrm{a}}$ & $84.20 \pm 3.28^{\mathbf{a , d}}$ & $104.40 \pm 3.11^{\mathbf{a}, \mathbf{d}, \mathbf{p}}$ & $57.20 \pm 4.57^{\mathbf{a , d}, \mathbf{p}, \mathbf{x}}$ \\
\hline ALT (IU/L) & $34.20 \pm 0.37$ & $57.60 \pm 3.54^{\mathrm{a}}$ & $78.60 \pm 3.78^{\mathrm{a}, \mathrm{d}}$ & $64.80 \pm 3.62^{\mathrm{a}, \mathrm{q}}$ & $46.80 \pm 2.15^{\mathbf{b , f}, \mathbf{p}, \mathbf{x}}$ \\
\hline ALP (IU/L) & $31.00 \pm 2.30$ & $56.74 \pm 4.65^{\mathrm{a}}$ & $54.95 \pm 3.92^{\mathrm{a}}$ & $59.79 \pm 4.90^{\mathrm{a}}$ & $54.18 \pm 1.58^{\mathrm{a}}$ \\
\hline AST:ALT & $0.48 \pm 0.04$ & $0.70 \pm 0.07$ & $1.09 \pm 0.09^{\mathbf{a}, \mathrm{e}}$ & $1.64 \pm 0.12^{\mathbf{a}, \mathbf{d}, \mathbf{p}}$ & $1.24 \pm 0.13^{\mathbf{a}, \mathbf{d}, \mathbf{y}}$ \\
\hline Total Bilirubin $(\mu \mathrm{mol} / \mathrm{L})$ & $11.92 \pm 0.40$ & $20.20 \pm 0.56^{\mathbf{c}}$ & $24.99 \pm 1.68^{\mathbf{b}}$ & $52.40 \pm 4.92^{\mathbf{a}, \mathbf{d}, \mathbf{p}}$ & $30.96 \pm 3.10^{\mathbf{a , f , x}}$ \\
\hline Conjugated Bilirubin $(\mu \mathrm{mol} / \mathrm{L})$ & $8.90 \pm 1.21$ & $3.62 \pm 0.30^{\mathbf{a}}$ & $4.04 \pm 0.42^{\mathrm{a}}$ & $5.58 \pm 0.15^{\mathrm{a}, \mathrm{f}}$ & $1.48 \pm 0.18^{\mathbf{a}, \mathbf{f}, \mathbf{q}, \mathbf{x}}$ \\
\hline Unconjugated Bilirubin $(\mu \mathrm{mol} / \mathrm{L})$ & $3.51 \pm 0.31$ & $16.58 \pm 0.80^{\mathbf{b}}$ & $20.95 \pm 1.42^{\mathrm{a}}$ & $46.82 \pm 5.00^{\mathbf{a}, \mathbf{d}, \mathbf{p}}$ & $29.48 \pm 3.25^{\mathbf{a}, \mathbf{r}, \mathbf{z}}$ \\
\hline Percentage Conjugation of Bilirubin (\%) & $74.56 \pm 9.86$ & $18.09 \pm 1.88^{\mathrm{a}}$ & $16.16 \pm 1.25^{\mathrm{a}}$ & $11.23 \pm 1.55^{\mathrm{a}}$ & $5.14 \pm 0.99^{\mathbf{a}}$ \\
\hline
\end{tabular}

Values are mean \pm SEM, $\mathrm{n}=5$.

$\mathrm{a}=\mathrm{p}<0.001, \mathrm{~b}=\mathrm{p}<0.01, \mathrm{c}=\mathrm{p}<0.05$ vs control; $\mathrm{d}=\mathrm{p}<0.001, \mathrm{e}=\mathrm{p}<0.01, \mathrm{f}=\mathrm{p}<0.05$ vs sildenafil;

$\mathrm{p}=\mathrm{p}<0.001, \mathrm{q}=\mathrm{p}<0.01, \mathrm{r}=\mathrm{p}<0.05$ vs tadalafil; $\mathrm{x}=\mathrm{p}<0.001, \mathrm{y}=\mathrm{p}<0.01, \mathrm{z}=\mathrm{p}<0.05$ vs tramadol

\section{Serum ALT concentration}

Serum ALT concentration for control, sildenafil, tadalafil, tramadol and sildenafil + tramadol treated groups were $34.20 \pm 0.37,57.60 \pm 3.54,78.60 \pm 3.78,64.80 \pm 3.62$ and $46.80 \pm$ 2.15 IU/L, respectively. Serum ALT concentration was significantly increased in sildenafil $(\mathrm{p}<0.001)$, tadalafil $(\mathrm{p}<0.001)$, tramadol $(\mathrm{p}<0.001)$ and sildenafil + tramadol treated group $(\mathrm{p}<0.01)$, compared with control. Tadalafil treated group had significantly $(\mathrm{p}<0.001)$ higher serum ALT concentration, while sildenafil + tramadol treated group had a significantly lower $(\mathrm{p}<0.05)$ ALT concentration, compared with sildenafil treated group (Table 2.0). Serum ALT concentration was significantly lower in tramadol treated group $(\mathrm{p}<0.01)$ and sildenafil + tramadol treated group $(\mathrm{p}<0.001)$, compared with tadalafil treated group. Also, serum ALT concentration was significantly $(\mathrm{p}<0.001)$ lower in sildenafil + tramadol treated group, compared with tramadol treated group (table 2.0).

\section{Serum ALP concentration}

Serum ALP concentration after 8 weeks of drug treatment was $31.00 \pm 2.30,56.74 \pm 4.65,54.95 \pm 3.92,59.79 \pm$ 4.90 and $54.18 \pm 1.58 \mathrm{IU} / \mathrm{L}$, for control, sildenafil, tadalafil, tramadol and sildenafil + tramadol treated groups. Serum ALP concentration was significantly $(\mathrm{p}<0.001)$ increased in sildenafil, tadalafil, tramadol and sildenafil + tramadol treated groups, compared with control (table 2.0).

\section{AST/ALT ratio}

The AST/ALT ratio after 8 weeks of drug treatment was $0.48 \pm 0.04,0.70 \pm 0.07,1.09 \pm 0.09,1.64 \pm 0.12$ and $1.24 \pm 0.13$, for control, sildenafil, tadalafil, tramadol and sildenafil + tramadol treated groups, respectively. The ratio of AST to ALT was significantly $(\mathrm{p}<0.001)$ higher in tadalafil, tramadol and sildenafil + tramadol treated groups, compared with control. It was also significantly higher in tadalafil $(\mathrm{p}<0.01)$, tramadol $(\mathrm{p}<0.001)$ and sildenafil + tramadol treated groups $(\mathrm{p}<0.001)$, compared with sildenafil treated group.

The ratio of AST to ALT was significantly $(\mathrm{p}<0.001)$ higher in tramadol treated group, compared with tadalafil treated group, and significantly $(\mathrm{p}<0.01)$ lower in sildenafil + tramadol treated group, compared with tramadol treated group (table 2.0).

\section{Serum total bilirubin concentration}

Serum total bilirubin concentration for control, sildenafil, tadalafil, tramadol and sildenafil + tramadol treated groups were $11.92 \pm 0.40,20.20 \pm 0.56,24.99 \pm 1.68,52.40 \pm 4.92$ and $30.96 \pm$ $3.10 \mu \mathrm{mol} / \mathrm{L}$, respectively. Serum total bilirubin concentration was significantly higher in sildenafil $(\mathrm{p}<0.05)$, tadalafil $(\mathrm{p}<0.01)$, tramadol $(\mathrm{p}<0.001)$ and sildenafil + tramadol treated group $(\mathrm{p}<0.001)$, compared with control. Total bilirubin concentration was significantly higher in tramadol $(\mathrm{p}<0.001)$ and sildenafil + tramadol treated group $(\mathrm{p}<0.05)$, compared with sildenafil treated group, and significantly $(\mathrm{p}<0.001)$ higher in tramadol treated group, compared with tadalafil and sildenafil + tramadol treated groups (table 2.0).

\section{Serum conjugated bilirubin concentration}

Following 8 weeks of drug administration, serum conjugated bilirubin concentration for control, sildenafil, tadalafil, tramadol and sildenafil + tramadol treated groups were $8.90 \pm$ $1.21,3.62 \pm 0.30,4.04 \pm 0.42,5.58 \pm 0.15$ and $1.48 \pm 0.18$ $\mu \mathrm{mol} / \mathrm{L}$, respectively. Serum conjugated bilirubin concentration was significantly $(\mathrm{p}<0.001)$ lower in sildenafil, tadalafil, tramadol and sildenafil + tramadol treated groups, compared with control. Serum conjugated bilirubin concentration was significantly $(\mathrm{p}<0.05)$ higher in tramadol treated group, but significantly $(\mathrm{p}<0.05)$ lower in sildenafil + tramadol treated group, compared with sildenafil treated group. Serum concentration of conjugated bilirubin was significantly lower in sildenafil + tramadol treated group, compared with tadalafil $(\mathrm{p}<0.01)$ and tramadol $(\mathrm{p}<0.001)$ treated groups (table 2.0).

\section{Serum unconjugated bilirubin concentration}

After 8 weeks of drug administration, serum unconjugated bilirubin concentration for control, sildenafil, tadalafil, tramadol and sildenafil + tramadol treated groups were $3.51 \pm 0.31,16.58 \pm 0.80,20.95 \pm 1.42,46.82 \pm 5.00$ and $29.48 \pm$ $3.25 \mu \mathrm{mol} / \mathrm{L}$, respectively. Serum unconjugated bilirubin concentration was significantly higher in sildenafil $(p<0.01)$, tadalafil $(\mathrm{p}<0.001)$, tramadol $(\mathrm{p}<0.001)$ and sildenafil + tramadol $(\mathrm{p}<0.001)$ treated groups, compared with control. Serum unconjugated bilirubin concentration was significantly $(\mathrm{p}<0.001)$ higher in tramadol treated group, compared with sildenafil treated 
group. Serum concentration of unconjugated bilirubin was significantly higher in tramadol $(\mathrm{p}<0.001)$ and sildenafil + tramadol $(\mathrm{p}<0.05)$ treated groups, compared with tadalafil treated group. Serum concentration of unconjugated bilirubin was significantly $(\mathrm{p}<0.05)$ lower in sildenafil + tramadol treated group, compared with tramadol treated group (table 2.0).

\section{Percentage conjugation of serum total bilirubin}

After 8 weeks of drug administration, the percentage conjugation of serum total bilirubin for control, sildenafil, tadalafil, tramadol and sildenafil + tramadol treated groups was $74.56 \pm 9.86,18.09 \pm 1.88,16.16 \pm 1.25,11.23 \pm 1.55$ and $5.14 \pm$ $0.99 \%$, respectively. Percentage conjugation of serum total bilirubin was significantly $(\mathrm{p}<0.001)$ lower in sildenafil, tadalafil, tramadol and sildenafil + tramadol treated groups, compared with control (table 2).

\section{Comparison of serum concentration of liver enzymes and bilirubin in the different experimental groups after 8 weeks of withdrawal of treatment}

\section{Serum AST concentration}

After 8 weeks of withdrawal of treatment, serum AST concentration for control, sildenafil, tadalafil, tramadol and sildenafil + tramadol treated groups was $15.20 \pm 1.02,23.00 \pm$ $1.92,66.80 \pm 4.47,38.00 \pm 2.26$ and $15.00 \pm 1.14 \mathrm{IU} / \mathrm{L}$, respectively. Serum AST concentration was significantly higher in sildenafil $(\mathrm{p}<0.05)$, tadalafil $(\mathrm{p}<0.001)$ and tramadol $(\mathrm{p}<0.001)$ treated groups, compared with control. Serum AST concentration was significantly higher in tadalafil $(\mathrm{p}<0.001)$ and tramadol $(\mathrm{p}<0.001)$ treated groups, but significantly lower in sildenafil + tramadol treated group $(\mathrm{p}<0.05)$, compared with sildenafil treated group. It was also significantly $(\mathrm{p}<0.001)$ lower in tramadol and sildenafil + tramadol treated groups, compared with tadalafil treated group. Serum AST concentration was significantly $(p<0.001)$ lower in sildenafil + tramadol treated group, compared with tramadol treated group (table 3 ).

\section{Serum ALT concentration}

Serum ALT concentration for control, sildenafil, tadalafil, tramadol and sildenafil + tramadol treated groups was
$35.2 \pm 0.80,44.4 \pm 1.40,55.00 \pm 3.39,45.60 \pm 4.79$ and $41.40 \pm$ 1.03 IU/L, respectively. Serum ALT concentration was significantly higher in sildenafil $(\mathrm{p}<0.05)$, tadalafil $(\mathrm{p}<0.001)$ and tramadol $(\mathrm{p}<0.05)$ treated groups, compared with control. Tadalafil and sildenafil + tramadol treated groups had significantly $(\mathrm{p}<0.05)$ lower serum ALT concentration, compared with sildenafil treated group.

Serum ALT concentration was significantly $(\mathrm{p}<0.05)$ lower in tramadol and sildenafil + tramadol treated groups, compared with tadalafil treated group (table 3.0).

\section{Serum ALP concentration}

Serum ALP concentration after 8 weeks of withdrawal of treatment was $30.40 \pm 2.87,61.60 \pm 3.78,50.20 \pm 4.15,87.80 \pm$ 4.47 and $50.40 \pm 1.89 \mathrm{IU} / \mathrm{L}$, for control, sildenafil, tadalafil, tramadol and sildenafil + tramadol treated groups. Serum ALP concentration was significantly $(\mathrm{p}<0.001)$ increased in sildenafil, tadalafil, tramadol and sildenafil + tramadol treated groups, compared with control. Serum ALP concentration was significantly $(p<0.001)$ higher in tramadol treated group, but significantly $(p<0.05)$ lower in tadalafil and sildenafil + tramadol treated groups, compared with sildenafil treated group. Serum ALP concentration was significantly $(\mathrm{p}<0.001)$ higher in tramadol treated group, compared with tadalafil and sildenafil + tramadol treated groups (table 3.0).

\section{AST/ALT ratio}

The AST/ALT ratio after 8 weeks of withdrawal of treatment was $0.43 \pm 0.03,0.52 \pm 0.04,1.23 \pm 0.09,0.87 \pm 0.09$ and $0.36 \pm 0.02$, for control, sildenafil, tadalafil, tramadol and sildenafil + tramadol treated groups, respectively. The ratio of AST to ALT was significantly $(\mathrm{p}<0.001)$ higher in tadalafil and tramadol treated groups, compared with control. It was also significantly $(\mathrm{p}<0.001)$ higher in tadalafil and tramadol treated groups, compared with sildenafil treated group.

The ratio of AST to ALT was significantly $(p<0.001)$ lower in tramadol treated group, compared with tadalafil treated group, and significantly $(\mathrm{p}<0.001)$ lower in sildenafil + tramadol treated group, compared with tramadol treated group (table 3 ).

Table 3: Comparison of serum concentration of liver enzymes and bilirubin in the different experimental groups following withdrawal of the various drugs for 8 weeks.

\begin{tabular}{|c|c|c|c|c|c|}
\hline Parameter & Control & Sildenafil & Tadalafil & Tramadol & Sild.+Tram. \\
\hline AST (IU/L) & $15.20 \pm 1.02$ & $23.00 \pm 1.92^{\mathrm{c}}$ & $66.80 \pm 4.47^{\mathrm{a}, \mathrm{d}}$ & $38.00 \pm 2.26^{\mathbf{a , d}, \mathbf{p}}$ & $15.00 \pm 1.14^{\mathbf{f}, \mathbf{p}, \mathbf{x}}$ \\
\hline ALT (IU/L) & $35.2 \pm 0.80$ & $44.4 \pm 1.40^{\mathrm{c}}$ & $55.00 \pm 3.39^{\mathrm{a}, \mathrm{f}}$ & $45.60 \pm 4.79^{\mathrm{c}, \mathbf{r}}$ & $41.40 \pm 1.03^{\mathrm{f}, \mathrm{r}}$ \\
\hline ALP (IU/L) & $30.40 \pm 2.87$ & $61.60 \pm 3.78^{\mathrm{a}}$ & $50.20 \pm 4.15^{\mathrm{a}, \mathrm{f}}$ & $87.80 \pm 4.47^{\mathbf{a}, \mathbf{d}, \mathbf{p}}$ & $50.40 \pm 1.89^{\mathbf{a}, \mathbf{f}, \mathbf{x}}$ \\
\hline AST:ALT & $0.43 \pm 0.03$ & $0.52 \pm 0.04$ & $1.23 \pm 0.09^{\mathbf{a}, \mathbf{d}}$ & $0.87 \pm 0.09^{\mathbf{a}, \mathbf{d}, \mathbf{p}}$ & $0.36 \pm 0.02^{\mathbf{p}, \mathbf{x}}$ \\
\hline Total Bilirubin $(\mu \mathrm{mol} / \mathrm{L})$ & $11.90 \pm 0.79$ & $18.17 \pm 2.24^{\mathbf{b}}$ & $19.94 \pm 0.88^{\mathbf{a}}$ & $44.86 \pm 1.73^{\mathbf{a}, \mathbf{d}, \mathbf{p}}$ & $10.79 \pm 0.55^{\mathbf{d}, \mathbf{p}, \mathbf{x}}$ \\
\hline Conjugated Bilirubin $(\mu \mathrm{mol} / \mathrm{L})$ & $8.78 \pm 1.14$ & $5.70 \pm 0.99^{\mathbf{b}}$ & $5.47 \pm 0.48^{\mathbf{b}}$ & $9.24 \pm 0.33^{\mathrm{e}, \mathrm{q}}$ & $1.78 \pm 0.07^{\mathbf{a}, \mathbf{e}, \mathbf{q}, \mathbf{x}}$ \\
\hline Unconjugated Bilirubin $(\mu \mathrm{mol} / \mathrm{L})$ & $3.12 \pm 0.47$ & $12.47 \pm 2.23^{\mathrm{a}}$ & $14.47 \pm 0.84^{\mathrm{a}}$ & $35.62 \pm 1.79^{\mathbf{a}, \mathbf{d}, \mathbf{p}}$ & $9.53 \pm 0.55^{\mathbf{b}, \mathbf{r}, \mathbf{x}}$ \\
\hline Percentage Conjugation of Bilirubin (\%) & $72.73 \pm 5.30$ & $32.68 \pm 7.05^{\mathrm{a}}$ & $27.52 \pm 2.15^{\mathrm{a}}$ & $20.73 \pm 1.15^{\mathrm{a}}$ & $16.69 \pm 1.15^{\mathrm{a}, \mathrm{f}}$ \\
\hline
\end{tabular}

Values are mean \pm SEM, $\mathrm{n}=5$.

$\mathrm{a}=\mathrm{p}<0.001, \mathrm{~b}=\mathrm{p}<0.01, \mathrm{c}=\mathrm{p}<0.05$ vs control; $, \quad \mathrm{d}=\mathrm{p}<0.001, \mathrm{e}=\mathrm{p}<0.01, \mathrm{f}=\mathrm{p}<0.05$ vs sildenafil

$\mathrm{p}=\mathrm{p}<0.001, \mathrm{q}=\mathrm{p}<0.01, \mathrm{r}=\mathrm{p}<0.05$ vs tadalafil;., $\quad \mathrm{x}=\mathrm{p}<0.001, \mathrm{y}=\mathrm{p}<0.01$ vs tramadol 


\section{Serum total bilirubin concentration}

Serum total bilirubin concentration for control, sildenafil, tadalafil, tramadol and sildenafil + tramadol treated groups was $11.90 \pm 0.79,18.17 \pm 2.24,19.94 \pm 0.88,44.86 \pm 1.73$ and $10.79 \pm$ $0.55 \mu \mathrm{mol} / \mathrm{L}$, respectively. Serum total bilirubin concentration was significantly higher in sildenafil $(\mathrm{p}<0.01)$, tadalafil $(\mathrm{p}<0.001)$ and tramadol $(\mathrm{p}<0.001)$ treated groups, compared with control. Total bilirubin concentration was significantly $(p<0.001)$ higher in tramadol treated group, but significantly $(\mathrm{p}<0.001)$ lower in sildenafil + tramadol treated group, compared with sildenafil treated group.

It was also was significantly $(\mathrm{p}<0.001)$ higher in tramadol treated group, but significantly $(\mathrm{p}<0.001)$ lower in sildenafil + tramadol treated group, compared with tadalafil treated group. Serum total bilirubin concentration was significantly $(\mathrm{p}<0.001)$ lower in sildenafil + tramadol treated group, compared with tramadol treated group (table 3.0).

\section{Serum conjugated bilirubin concentration}

Following 8 weeks of withdrawal of drug administration, serum conjugated bilirubin concentration for control, sildenafil, tadalafil, tramadol and sildenafil + tramadol treated groups was $8.78 \pm 1.14,5.70 \pm 0.99,5.47 \pm 0.48,9.24 \pm 0.33$ and $1.78 \pm 0.07$ $\mu \mathrm{mol} / \mathrm{L}$, respectively.

Serum conjugated bilirubin concentration was significantly lower in sildenafil $(\mathrm{p}<0.01)$, tadalafil $(\mathrm{p}<0.01)$ and sildenafil + tramadol $(p<0.001)$ treated groups, compared with control. Serum conjugated bilirubin concentration was significantly $(p<0.01)$ higher in tramadol treated group, but significantly $(\mathrm{p}<0.01)$ lower in sildenafil + tramadol treated group, compared with sildenafil treated group. It was also significantly $(\mathrm{p}<0.01)$ higher in tramadol treated group, but significantly $(\mathrm{p}<0.01)$ lower in sildenafil + tramadol treated group, compared with tadalafil treated group. Serum concentration of conjugated bilirubin was significantly $(\mathrm{p}<0.001)$ lower in sildenafil + tramadol treated group, compared with tramadol treated group (table 3.0).

\section{Serum unconjugated bilirubin concentration}

After 8 weeks of withdrawal of drug administration, serum unconjugated bilirubin concentration for control, sildenafil, tadalafil, tramadol and sildenafil + tramadol treated groups was $3.12 \pm 0.47,12.47 \pm 2.23,14.47 \pm 0.84,35.62 \pm 1.79$ and $9.53 \pm$ $0.55 \mu \mathrm{mol} / \mathrm{L}$, respectively. Serum unconjugated bilirubin concentration was significantly higher in sildenafil $(\mathrm{p}<0.001)$, tadalafil $(\mathrm{p}<0.001)$, tramadol $(\mathrm{p}<0.001)$ and sildenafil + tramadol $(\mathrm{p}<0.01)$ treated groups, compared with control. Serum unconjugated bilirubin concentration was significantly $(\mathrm{p}<0.001)$ higher in tramadol treated group, compared with sildenafil treated group.

Serum concentration of unconjugated bilirubin was significantly higher in tramadol $(\mathrm{p}<0.001)$ treated group, but significantly $(\mathrm{p}<0.01)$ lower in sildenafil + tramadol treated group, compared with tadalafil treated group. Serum concentration of unconjugated bilirubin was significantly $(\mathrm{p}<0.001)$ lower in sildenafil + tramadol treated group, compared with tramadol treated group (table 3.0).

\section{Percentage conjugation of serum total bilirubin}

After 8 weeks of withdrawal of drug administration, the percentage conjugation of serum total bilirubin for control, sildenafil, tadalafil, tramadol and sildenafil + tramadol treated groups was $72.73 \pm 5.30,32.68 \pm 7.05,27.52 \pm 2.15,20.73 \pm 1.15$ and $16.69 \pm 1.15 \%$, respectively. Percentage conjugation of serum total bilirubin was significantly $(p<0.001)$ lower in sildenafil, tadalafil, tramadol and sildenafil + tramadol treated groups, compared with control. Percentage conjugation of serum total bilirubin was significantly $(\mathrm{p}<0.05)$ lower in sildenafil + tramadol treated group, compared with sildenafil treated group (table 3.0).

\section{Comparison of serum concentration of liver enzymes and bilirubin between treated and recovery groups Serum AST concentration}

There was no significant difference in serum AST concentration between the treated and recovery control groups. Serum AST concentration was significantly reduced in sildenafil $(\mathrm{p}<0.01)$, tadalafil $(\mathrm{p}<0.05)$, tramadol $(\mathrm{p}<0.001)$ and sildenafil + tramadol $(\mathrm{p}<0.001)$ recovery groups, compared with their respective treated groups (figure 1).

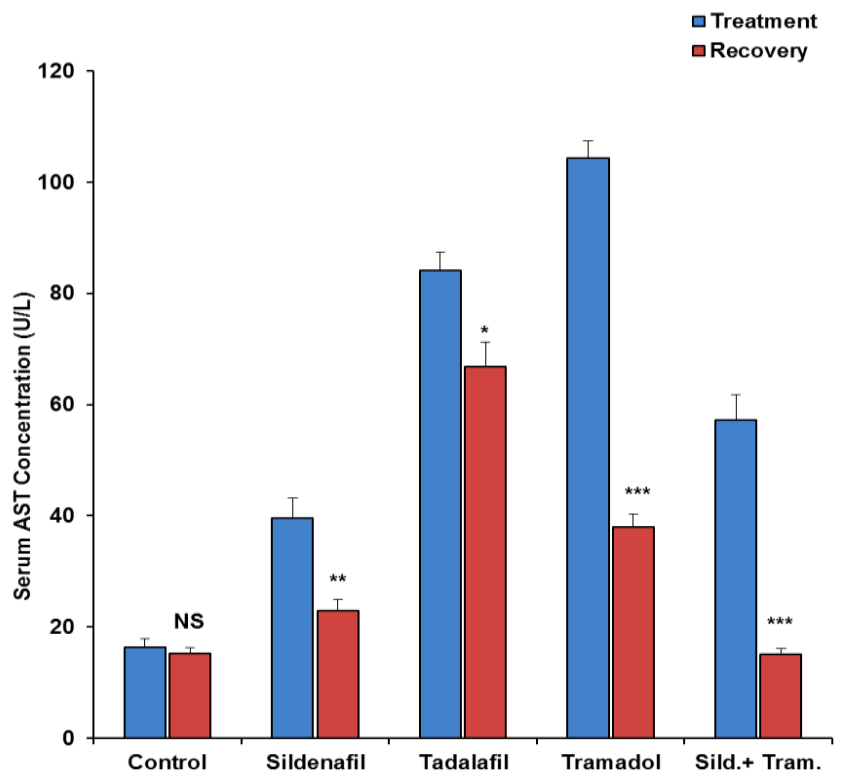

Fig. 1: Comparison of serum AST concentration between the treated and recovery groups. Values are mean $\pm \mathrm{SEM}, \mathrm{n}=5$.

${ }^{*} \mathrm{p}<0.05, * * \mathrm{p}<0.01, * * * \mathrm{p}<0.001$ vs treatment; NS $=$ not significant.

\section{Serum ALT concentration}

There was no significant difference in serum ALT concentration between the treated and recovery control groups. Serum ALT concentration was significantly reduced in sildenafil $(p<0.01)$, tadalafil $(p<0.01)$ and tramadol $(p<0.05)$ recovery groups, compared with their respective treated groups. There was 
no significant difference in serum ALT concentration between the treated and recovery groups of animals administered sildenafil + tramadol (figure 2).

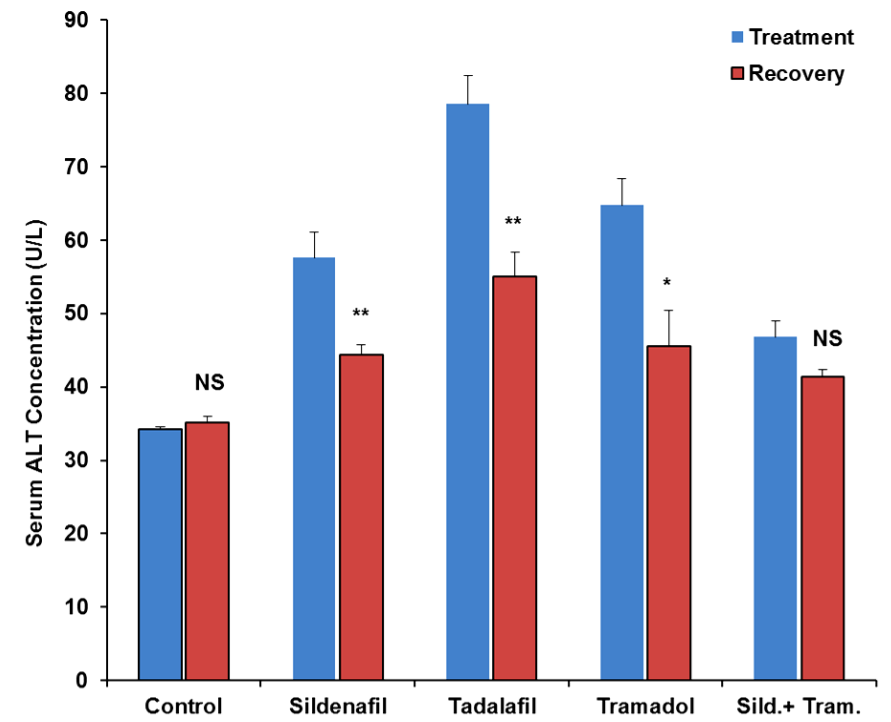

Fig. 2: Comparison of serum ALT concentration between the treated and recovery groups. Values are mean $\pm \mathrm{SEM}, \mathrm{n}=5$.

$* \mathrm{p}<0.05,{ }^{*} \mathrm{p}<0.01$ vs treatment; NS $=$ not significant.

\section{Serum ALP concentration}

There was no significant difference in serum ALP concentration between the treated and recovery control groups. Also, serum ALP concentration for sildenafil, tadalafil and sildenafil + tramadol recovery groups were not significantly different from their respective treated groups. Furthermore, serum ALP concentration was significantly $(\mathrm{p}<0.01)$ increased in tramadol recovery group, compared with its treated group (figure 3).

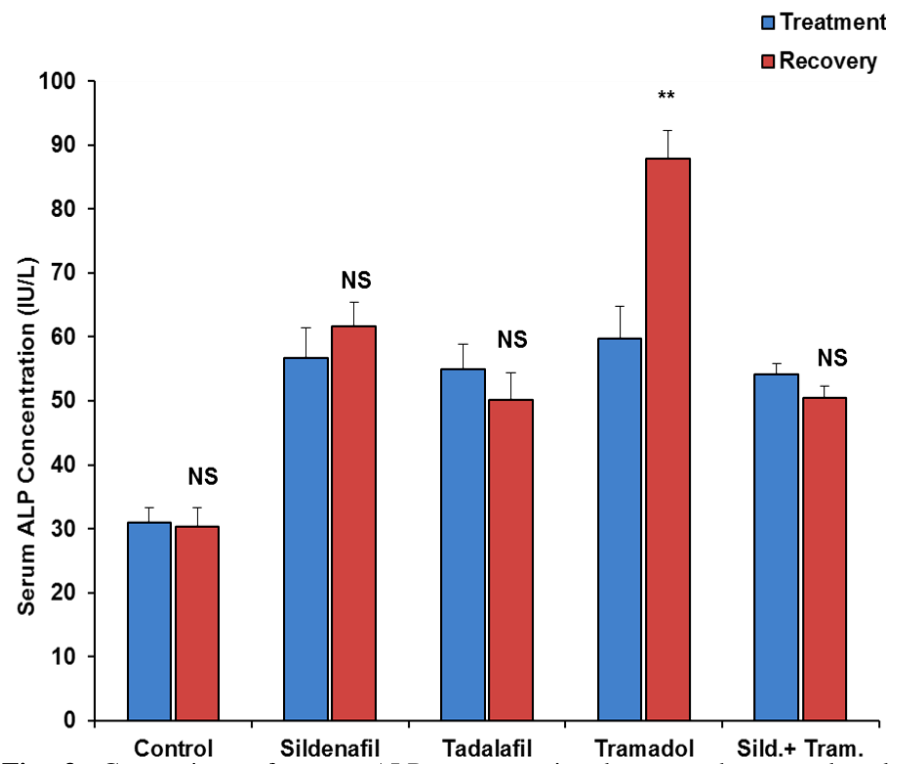

Fig. 3: Comparison of serum ALP concentration between the treated and recovery groups. Values are mean $\pm \mathrm{SEM}, \mathrm{n}=5$.

$* * \mathrm{p}<0.01$ vs treatment; NS = not significant.

\section{AST/ALT ratio}

There was no significant difference in AST:ALT ratio between the treated and recovery control groups. The ratio of AST to ALT in sildenafil and tadalafil recovery groups did not significantly differ from the treated groups. Furthermore, AST:ALT ratio was significantly reduced in tramadol $(\mathrm{p}<0.001)$ and sildenafil + tramadol $(\mathrm{p}<0.001)$ recovery groups, compared with their respective treated group (figure 4).

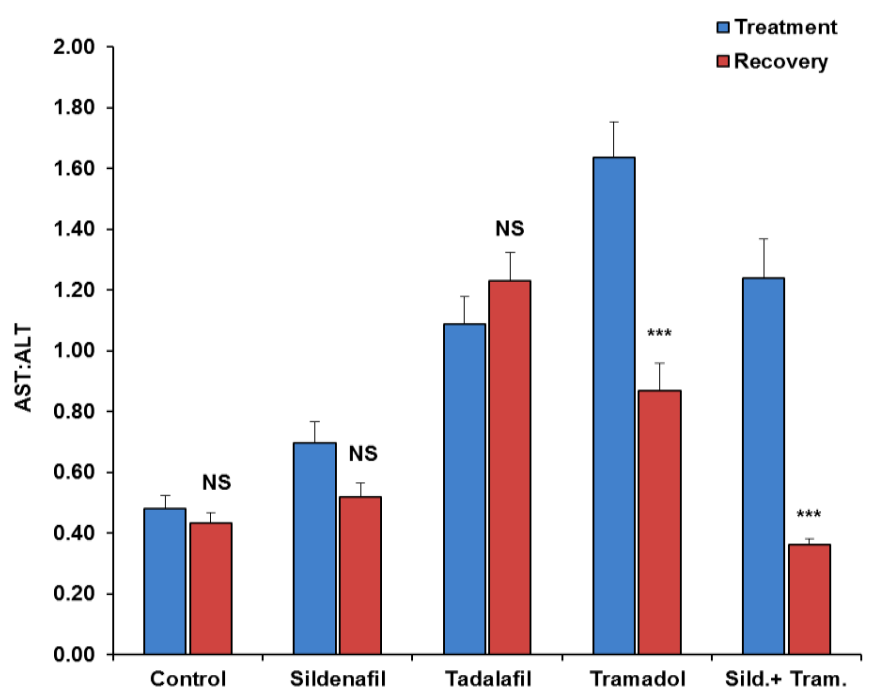

Fig. 4: Comparison of AST/ALT ratio between the treated and recovery groups.

Values are mean \pm SEM, $\mathrm{n}=5$.

$* * \mathrm{p}<0.001$ vs treatment; $\mathrm{NS}=$ not significant.

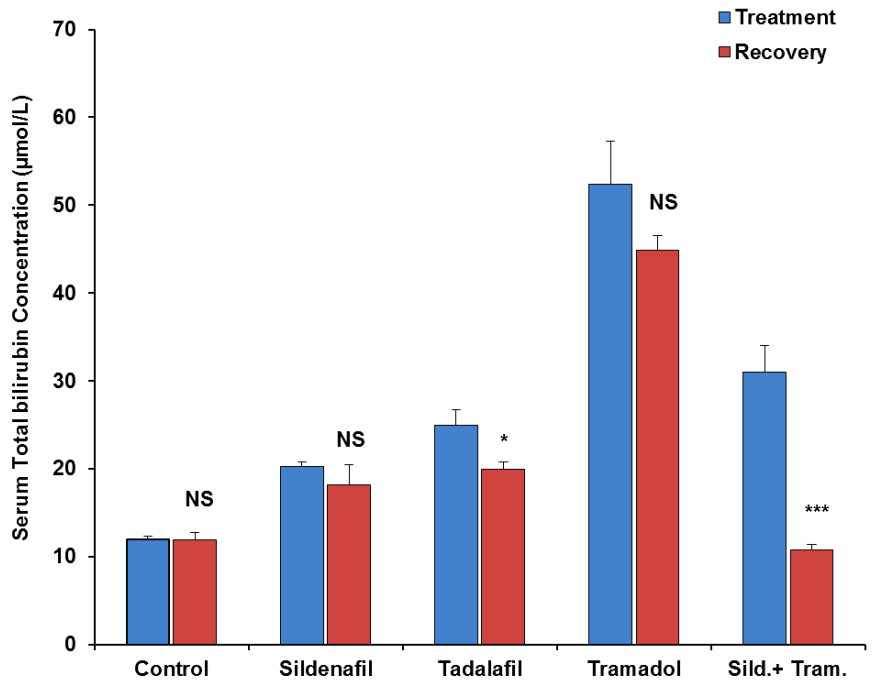

Fig. 5: Comparison of serum total bilirubin concentration between the treated and recovery groups. Values are mean $\pm \mathrm{SEM}, \mathrm{n}=5$.

${ }^{*} \mathrm{p}<0.05, * * * \mathrm{p}<0.001$ vs treatment; NS $=$ not significant

\section{Serum total bilirubin concentration}

There was no significant difference in serum total bilirubin concentration between the treated and recovery control groups. Serum total bilirubin concentration was significantly reduced in tadalafil $(\mathrm{p}<0.05)$ and sildenafil + tramadol $(\mathrm{p}<0.001)$ 
recovery groups, compared with their respective treated groups. There was no significant difference in serum total bilirubin concentration between the treated and recovery groups of animals administered sildenafil and tramadol, respectively (figure 5).

\section{Serum conjugated bilirubin concentration}

There was no significant difference in serum conjugated bilirubin concentration between the treated and recovery control groups. Serum conjugated bilirubin concentration was significantly $(\mathrm{p}<0.001)$ increased in tramadol recovery group, compared with its treated group. Although serum conjugated bilirubin concentration was increased in sildenafil, tadalafil and sildenafil + tadalafil recovery groups, there were not significantly different from their respective treated groups (figure 6).

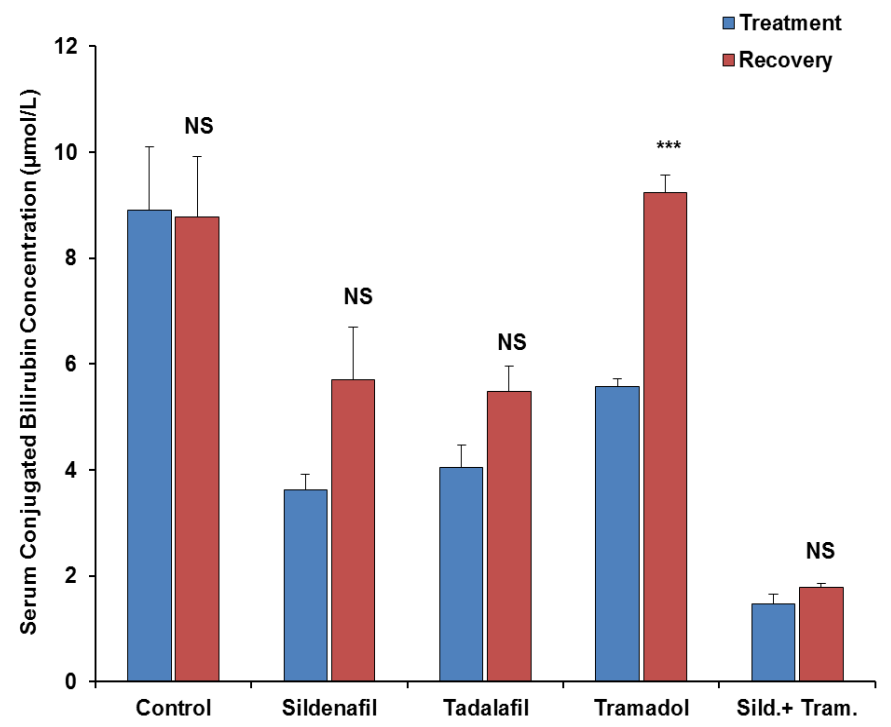

Fig. 6: Comparison of serum conjugated bilirubin concentration between the treated and recovery groups. Values are mean \pm SEM, $n=5$.

$* * * \mathrm{p}<0.001$ vs treatment; NS = not significant

\section{Serum unconjugated bilirubin concentration}

There was no significant difference in serum unconjugated bilirubin concentration between the treated and recovery control groups. Also, there was no significant difference in serum unconjugated bilirubin concentration in sildenafil and tramadol recovery groups, compared with their respective treated groups. Serum unconjugated bilirubin concentration was significantly reduced in tadalafil $(\mathrm{p}<0.01)$ and sildenafil + tramadol $(\mathrm{p}<0.001)$ recovery groups, compared with their respective treated groups (figure 7).

\section{Percentage conjugation of serum total bilirubin}

There was no significant difference in percentage conjugation of serum total bilirubin between the treated and recovery control groups. Percentage conjugation of serum total bilirubin was significantly higher in tadalafil $(\mathrm{p}<0.01)$, tramadol $(\mathrm{p}<0.01)$ and sildenafil + tramadol recovery groups, compared with their respective treated groups. There was no significant difference in percentage conjugation of serum total bilirubin between sildenafil recovery and treated groups, though the recovery group showed higher percentage conjugation of serum total bilirubin (figure 8).

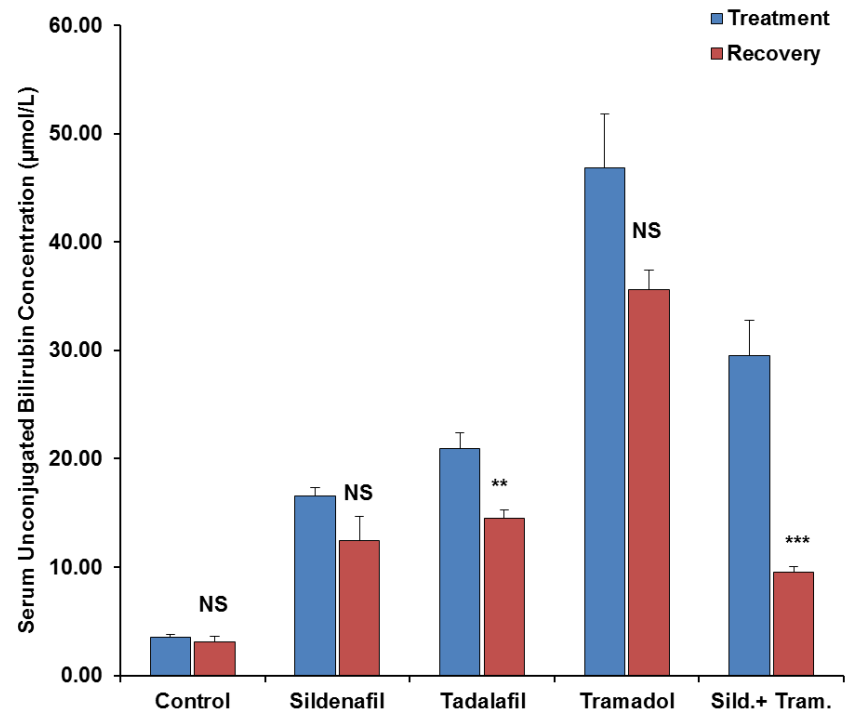

Fig. 7: Comparison of serum unconjugated bilirubin concentration between the treated and recovery groups. Values are mean $\pm S E M, n=5$.

** $\mathrm{p}<0.01, * * * \mathrm{p}<0.001$ vs treatment; NS $=$ not significant.

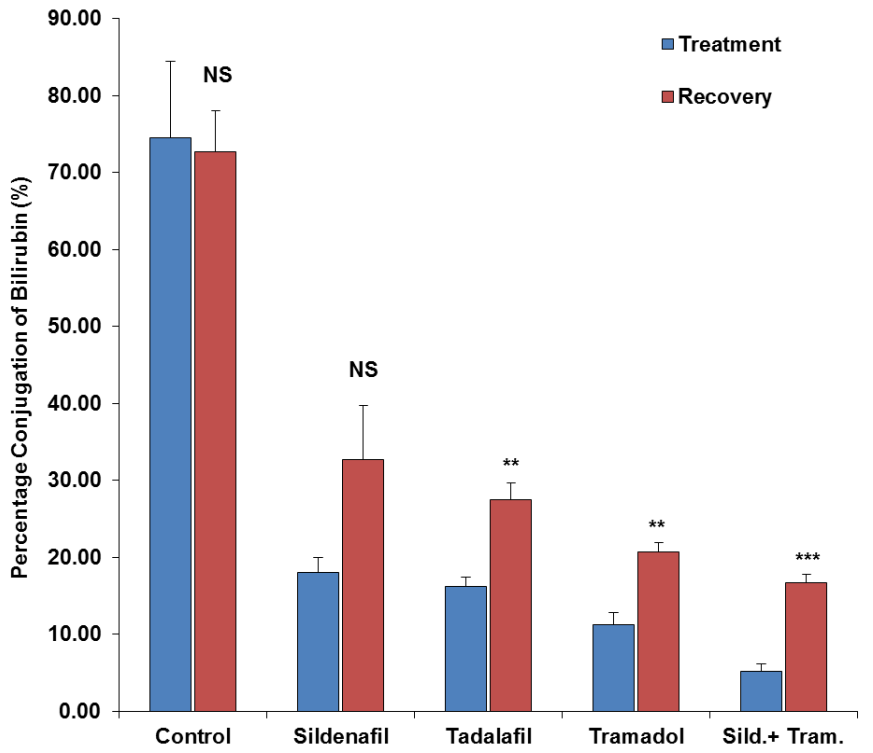

Fig. 8: Comparison of percentage of bilirubin conjugated by the liver between the treated and recovery groups. Values are mean \pm SEM, $n=5$.

$* * \mathrm{p}<0.01, * * * \mathrm{p}<0.001 \mathrm{vs}$ treatment; NS $=$ not significant.

\section{DISCUSSION}

The liver plays a major role in metabolism, and has a number of functions in the body, including glycogen storage, plasma protein synthesis, detoxification of most substances, and production of bile; an alkaline compound which aids in digestion (Gartner and Hiatt, 2000). Furthermore, the liver is known to form some metabolites in the process of metabolizing various substances. These metabolites (if harmful) are then packaged for 
excretion. This appears to form the basis of the liver damage observed in this present study since a high concentration of the metabolites of these drugs will be formed by the liver during their metabolism.

Serum aminotransferase assays are the most common laboratory tests for the detection of liver diseases. Commonly available tests include alanine transaminase (ALT), aspartate transaminase (AST), alkaline phosphatase (ALP), gamma glutamyl transferase, serum bilirubin, prothrombin time and serum albumin concentration, among others. They reflect different functions of the liver which include; excreting anions, hepatocellular integrity, formation and the subsequent free flow of bile, and protein synthesis. The present study showed significant increase in serum concentrations of AST, ALT and ALP in the groups administered sildenafil, tadalafil, tramadol and sildenafil + tramadol. Serum concentrations of AST and ALP were highest in tramadol treated group, while ALT concentration was highest in tadalafil treated group. The raised liver enzymes activity after 8 weeks of drug administration is indicative of liver damage. Eweka \& Eweka, (2011) had previously reported that sildenafil administered for 6 weeks resulted in severe hepatotoxicity as evident in their study which showed atrophic and degenerative changes in the liver.

Bilirubin concentration is elevated in the blood either by increased synthesis, reduced conjugation, reduced secretion by the liver, or blockage of the bile ducts. In cases of increased production, or decreased conjugation, the unconjugated or indirect form of bilirubin will be elevated. Again, the group administered tramadol had the highest serum concentration of total and unconjugated bilirubin. This shows that hepatotoxicity may have been greatest in this group. Serum conjugated bilirubin concentration was lowest in the group administered sildenafil + tramadol. A similar trend was observed for percentage conjugation of serum total bilirubin. In this study, the elevated bilirubin concentration may be as a result of decreased conjugation by the liver since the conjugated bilirubin concentration was relatively low in the treated groups. Again, this points to possible functional hepatotoxicity which reduces the liver's ability to conjugate bilirubin. Worthy of note also, is the fact that, the medications may be negatively affecting red blood cells and causing hemolysis. This may account for the increased total bilirubin concentration observed in the treated groups, since bilirubin is a product of hemoglobin catabolism. Unconjugated hyper bilirubinemia is caused by accelerated erythrocyte hemolysis (Sgro et al., 2006) such as that seen in the new born (erythroblastosis fetalis), absence of glucuronyl transferase, or hepatocellular disease (Guyton \& Hall, 2010). Conjugated hyper bilirubinemia on the other hand, is caused by obstruction of the biliary ducts, as with gallstones or hepatocellular diseases, such as, cirrhosis or hepatitis. Elevated serum bilirubin may also be caused by the effects of many different drugs like; antibiotics, barbiturates, steroids or oral contraceptives. In chronic acquired liver diseases, the serum bilirubin concentration is usually normal until a significant amount of liver damage has occurred, and cirrhosis is present. Our study portrays a chronic liver damage. A decrease in the percentage conjugation of serum total bilirubin in the treated groups $(18.09 \pm$ $1.88,16.16 \pm 1.25,11.23 \pm 1.55$ and $5.14 \pm 0.99 \%$, for sildenafil, tadalafil, tramadol and sildenafil + tramadol group, respectively) compared with that of control $(74.56 \pm 9.86 \%)$ further supports the fact that chronic liver damage may be implicated in the treated groups.

Following withdrawal of the various medications, evidence of reversal of hepatotoxicity was observed. From the results shown in table 3, where the reversal values for serum concentration of liver enzymes and bilirubin were compared with control, it appears that reversal of hepatotoxicity was poor. Serum concentration of liver enzymes and bilirubin still remained significantly different from control values (table 3). Furthermore, comparing the recovery groups with their respective treated groups (Figures 1-8), we observed that hepatotoxicity was poorly reversed.

\section{CONCLUSION}

Chronic administration of either sildenafil, tadalafil, tramadol or a combination of sildenafil and tramadol (as used in Nigeria today), caused significant alteration in liver functions as evident in the increased serum concentration of liver enzymes and bilirubin, and decrease in the percentage conjugation of serum bilirubin. The alteration was highest in the tramadol treated group and lowest in sildenafil treated group. None of the treated groups recorded complete reversal of hepatotoxicity following withdrawal of treatment. Hence, we strongly advocate for a campaign against abuse of ED medications.

\section{Conflict of interest}

We hereby declare that we have no conflict of interest.

\section{REFERENCES}

Althof SE, Abdo CH, Dean J, Hackett G, McCabe M, McMahon CG, Tan HM. International Society for Sexual Medicine's guidelines for the diagnosis and treatment of premature ejaculation. The Journal of Sexual Medicine, 2007; 7(9): 2947-2969.

Aluko EO, Olubobokun TH, Adekunbi DA, Nna VU. Sexual functions, sexual organs and sex hormone levels in chronic alcohol intake. British Journal of Medicine and Medical Research, 2014; 4(6): 1279-1292.

Benchekroun A, Faik M, Benjelloun S. A baseline-controlled, open-label, flexible dose-escalation study to assess the safety and efficacy of sildenafil citrate (Viagra) in patients with erectile dysfunction. International Journal of Impotence Research, 2003; 15(Suppl. 1):S19S24.

Bhutia DR, Upadhyay B, Meneesh M. Association of plasma level of thiobarbituric acid reactive substances with extent of hepatocellular injury in preterin infants with cholestatic jaundice. Indian J Clin. Biochem, 2006; 21(2):39-41.

Boolell M, Allen MJ, Ballard SA. Oral sildenafil: an orally active type 5 cyclic GMP specific phosphodiesterase inhibitor for the treatment of penile erectile dysfunction. International Journal of Impotence Research, 1996; 8: 47-52.

Eweka AO, Eweka A. The effects of sildenafil citrate on the liver and kidneys of adult wistar rats (Rattus norvegicus) - A Histological Study. In: Azita G, ed. Sexual Dysfunctions -Special Issues, 2011; 59-65.

Gartner LP, Hiatt JL. 2000. Color Atlas of Histology. Lippincott Williams \& Wilkins. 
Gopalakrishnan R, Jacob KS, Kuruvilla A, Vasantharaj B, John JK. Sildenafil in the treatment of antipsychotic-induced erectile dysfunction: a randomized, double-blind, placebo-controlled, flexibledose, two-way crossover trial. The American Journal of Psychiatry, 2006; 163(3):494-499.

Guyton AC, Hall JE. 2000. Textbook of medical physiology (10 ${ }^{\text {th }}$ ed.). Philadelphia: W. B. Saunders. pp $386-387$.

Kokkinos P, Tsimploulis A, Faselis C. 2015. PDE5 inhibitors for the treatment of erectile dysfunction in patients with hypertension. In Erectile Dysfunction in Hypertension and Cardiovascular Disease. Springer International Publishing. 185-193.

Nna VU, Ani EJ, Ofutet EO, Ofem OE, Iroh CE, Osim EE. Recurrent side effects following chronic recreational use of sexual stimulants among male subjects in Calabar, Cross River State, Nigeria. Der Pharmacia Lettre, 2014a; 6(6): 56-61.

Nna VU, Ofem OE, Oka VO, Aluko EO, Ofutet EO. Comparative effects of Aloe vera gel and aqueous leaf extract of Viscum album on bilirubin excretion in streptozotocin-induced diabetic rats. International Journal of Biochemistry Research and Review, 2014c; 4(1):99-115.

Nna VU, Ofem OE, Osim EE. Prevalence of sexual stimulant abuse unrelated to presence of erectile dysfunction among male subjects in Calabar, Cross River State, Nigeria. International Union of Physiological Sciences (IUPS)/34 ${ }^{\text {th }}$ Annual Scientific Conference of the Physiological Society of Nigeria, 20 - 21 October, 2014b.

Nurnberg HG, Gelenberg A, Hargreave TB, Harrison WM, Siegel RL, Smith MD. Efficacy of sildenafil citrate for the treatment of erectile dysfunction in men taking serotonin reuptake inhibitors. The American Journal of Psychiatry, 2001; 158(11):1926-1928.

Reitman S, Frankel SA. Calorimetric method of determination of serum glutamic oxaloacetic and glutamic pyruvate transaminase. Am J. Clin. Path, 1957; 28:56-67.
Rosen R, Porst H, Montorsi F. The premature ejaculation prevalence and attitudes (PEPA) survey: a multi-national survey [abstract]. Proceedings of the 11th World Congress of the International Society of Sexual and Impotence Research, 17-21 October 2004.

Rowland D, McMahon CG, Abdo C, Chen J, Jannini E, Waldinger MD, Ahn TY. Disorders of orgasm and ejaculation in men. The Journal of Sexual Medicine, 2010; 7(4pt2): 1668-1686.

Safarinejad MR, Hosseini SY. Safety and efficacy of tramadol in the treatment of premature ejaculation: a double-blind, placebocontrolled, fixed-dose, randomized study. Journal of Clinical Psychopharmacology, 2006; 26(1), 27-31.

Salem EA, Wilson SK, Bissada NK, Delk JR, Hellstrom WJ, Cleves MA. Tramadol HCL has Promise in On-Demand Use to Treat Premature Ejaculation. The Journal of Sexual Medicine, 2008; 5(1): 188193.

Sgro M, Campbell D, Shah V. Incidence and causes of severe neonatal hyperbilirubinemia in Canada. Canadian Medical Association Journal, 2006; 175(6), 587-590.

Sherlock S, Lunec J. Free radical and antioxidant system in health and disease. British Journal of Hospital Medicine, 1951; 43:334344.

\section{How to cite this article:}

Victor U. Nna, Ubom P. Akpan, Victoria E. Okon, Item J. Atangwho. Hepatotoxicity following separate administration of two phosphodiesterase-5 inhibitors (sildenafil \& tadalafil) and opioid (tramadol); evaluation of possible reversal following their withdrawal. J App Pharm Sci, 2015; 5 (08): 105-113. 